\begin{tabular}{|l|l|l|}
\hline Revista & & $\begin{array}{l}\text { Revista Latina de Sociologia (RELASO) } \\
\text { Vol. 9, núm. 2 (2019), pp. 24-58 } \\
\text { ISSN-e 2253-6469 } \\
\text { Datina }\end{array}$ \\
de Sociologs://doi.org/10.17979/relaso.2019.9.2.6826 & \\
\hline
\end{tabular}

\title{
Rompiendo brechas: propuesta de orientación sociolaboral con víctimas de violencia de género
}

\author{
Breaking the gap: a proposal for a socio-occupational guidance service \\ for victims of gender-based violence
}

Sonia Verdugo-Castro Grupo de Investigación GRIAL, Universidad de Salamanca, España soniavercas@usal.es ORCID: https://orcid.org/0000-0002-9357-1747

$M^{a}$ Cruz Sánchez-Gómez Grupo de Investigación GRIAL, Universidad de Salamanca, España mcsago@usal.es ORCID: https://orcid.org/0000-0003-4726-7143

Alicia García-Holgado Grupo de Investigación GRIAL, Universidad de Salamanca, España aliciagh@usal.es ORCID: https://orcid.org/0000-0001-9663-1103

Francisco José García-Peñalvo Grupo de Investigación GRIAL, Universidad de Salamanca, España fgarcia@usal.es ORCID: https://orcid.org/0000-0001-9987-5584 


\begin{tabular}{|l|l|l|}
\hline Revista & $\begin{array}{l}\text { Revista Latina de Sociología (RELASO) } \\
\text { Vol. 9, núm. 2 (2019), pp. 24-58 } \\
\text { ISSN-e 2253-6469 } \\
\text { Dot: https://doi.org/10.17979/relaso.2019.9.2.6826 }\end{array}$ \\
\hline
\end{tabular}

\section{Resumen}

Se ha llevado a cabo un estudio empírico en un municipio de España con nueve entidades del Tercer Sector que trabajan con mujeres víctimas de violencia de género con el objetivo de plantear una propuesta de intervención basada en la orientación sociolaboral, adecuada a las necesidades específicas de las destinatarias de las asociaciones participantes en el estudio. Para ello se ha investigado sobre el perfil laboral, formativo y familiar de las mujeres atendidas en las asociaciones y sobre las acciones de orientación sociolaboral desarrolladas en las entidades. El estudio se ha abordado desde la metodología cualitativa, con corte fenomenológico. Se han aplicado entrevistas semiestructuradas a cinco personas trabajadoras de las nueve entidades. Las cinco personas entrevistadas para el estudio prestan sus servicios a más de una de las entidades, por medio de la sinergia que se establece entre las asociaciones del Tercer Sector. Además de la información recogida a través de las entrevistas semiestructuradas, en otros casos, la información recogida, si bien no pudo ser grabada por protección de datos y privacidad, sí se recogió mediante memorias anuales facilitadas para el fin de la investigación. De esta manera, se contó con entrevistas y con material en formato de memorias; y mediante análisis clásico de contenido se han analizado los discursos y el contenido con el apoyo del CAQDAS Nvivo 12. Uno de los principales resultados del estudio ha sido el perfil de mujer atendida en el contexto; se trata mayormente de ciudadanas de nacionalidad española, de mediana edad, con responsabilidades familiares, en situación de desempleo y baja cualificación profesional. A partir de los discursos y los contenidos analizados se ha comprobado que, si bien algunas de las entidades desarrollan acciones sociolaborales, otras no cuentan con este servicio por carencia de recursos apropiados para el fin. Finalmente, se diseña una propuesta de intervención sociolaboral para potenciar la autonomía y empoderamiento de la mujer. La propuesta nace de las necesidades específicas del contexto y considerando el tejido social de la comunidad.

\section{Palabras clave}

Orientación profesional; elección profesional; desempleado; grupo desfavorecido; violencia doméstica; desarrollo de las habilidades; educación y empleo; necesidades educacionales

\footnotetext{
Abstract

The article presents the results of an empirical study carried out in a city in Spain with nine third-sector organisations that work with victims of gender-based violence. The aim of the study was to present a proposal for a socio-occupational guidance service adapted to the specific needs of the beneficiaries of the associations involved in the study. Research was conducted into the employment, educational and family situation of the women attended to by these organisations and into the socio-occupational guidance measures currently in place. The study used a qualitative phenomenological methodology, consisting of semi-structured interviews with five employees of the nine associations. The synergies between third-sector organisations are reflected in the fact that all five of the employees interviewed for the study provide their services to more than one of the associations. Information that could not be 


\begin{tabular}{|l|l|l|}
\hline Revista & & $\begin{array}{l}\text { Revista Latina de Sociologia (RELASO) } \\
\text { Vol. 9, núm. 2 (2019), pp. 24-58 } \\
\text { ISSN-e 2253-6469 } \\
\text { Dor: https://doi.org/10.17979/relaso.2019.9.2.6826 }\end{array}$ \\
de Sociologia & &
\end{tabular}

recorded for data protection and privacy reasons was obtained from annual reports made available for research purposes. The data collected through these two techniques (interviews and reports) were then subjected to a classical content analysis using CAQDAS Nvivo 12. One of the main findings of the study was the profile of the women who use these services: Spanish, middle-aged, with family responsibilities, unemployed and lacking professional qualifications. The content analysis of the data revealed that, although some of the associations carry out social and employment actions, others do not provide these services owing to the lack of appropriate resources. The article concludes with a proposal for a sociooccupational guidance service to promote the autonomy and empowerment of women. The proposal is based on the specific needs of the context of study and takes into account the social characteristics of the community.

\section{Keywords}

vocational and professional guidance; professional choice; unemployment; disadvantaged groups; domestic violence; skills development; education and employment; educational needs.

\section{Introducción}

Existe una realidad que afecta a nivel internacional y se trata de la brecha de género que existe en el ámbito laboral. En el estudio presentado por Verdugo-Castro et al. (2019) en el $8^{\circ}$ Congreso Iberoamericano de Investigación Cualitativa (CIAIQ2019), se mostraba la problemática que se encuentra en el ámbito de la ciencia, la tecnología, las ingenierías y las matemáticas en relación con la infrarrepresentación de las mujeres en el campo.

El momento social y económico actual ha marcado un crecimiento en el desarrollo y manejo de las nuevas tecnologías. Por ello, las áreas de ciencia, tecnología, ingeniería y matemáticas han tomado relevancia; si bien, este hecho no implica que sean más importantes que otras áreas, debido a que los demás sectores, como el área de artes y humanidades albergan una amplia interdisciplinariedad, resultando potentes combinaciones como las humanidades digitales. El peso que estas áreas han cogido es visible en tanto que la Fundación del Mercado Social ha revelado que ante las necesidades originadas en los últimos cinco años se requieren al menos 40.000 personas cualificadas en estas materias para responder a la emergente demanda del mercado laboral (Codiroli, 2017). Esta necesidad de personal cualificado, además, irá aumentando progresivamente con el paso de los años (Winterbotham, 2014). No obstante, las disparidades de género (Diekman et al., 2010) han hecho visible la brecha de género que afecta especialmente a mujeres y minorías, en tanto que representando a más del 50\%, incluso en algunos casos hasta el 70\% del alumnado universitario, son grupos infrarrepresentados en el ámbito educativo señalado, representando solamente al 25\% en algunos casos y no superando en ninguno de ellos al 50\% del alumnado 


\begin{tabular}{|l|l|l|}
\hline Revista & & $\begin{array}{l}\text { Revista Latina de Sociologia (RELASO) } \\
\text { Vol. 9, núm. 2 (2019), pp. 24-58 } \\
\text { ISSN-e 2253-6469 } \\
\text { DoI: https://doi.org/10.17979/relaso.2019.9.2.6826 }\end{array}$ \\
de Sociologia & &
\end{tabular}

en el sector educativo (Blackburn, 2017; European Institute of Gender Equality, 2018; García-Holgado et al., 2018).

En el estudio de Verdugo-Castro et al. (2019) se enfoca la problemática de la brecha de género en los estudios superiores relacionado con el campo científico y técnico a través de una metodología de investigación centrada en el trabajo de campo, con un corte cualitativo y de enfoques mixtos.

En la línea de la metodología cualitativa se presenta en el artículo una investigación realizada en paralelo a la indicada, sobre la influencia que tiene el mercado laboral para la mujer, sin embargo, en esta ocasión desde el punto de vista de la posición de exclusión social.

El presente artículo presenta la investigación realizada en 2017 con entidades del Tercer Sector que trabajan con mujeres víctimas de violencia de género, y sobre la necesidad de ampliar la orientación sociolaboral dirigida hacia las mismas, con el objetivo de fomentar los principios de igualdad y equilibrio en la esfera laboral de la mujer, y, por tanto, la mejoría y desarrollo del empoderamiento integral como persona.

La investigación se centró en la necesidad de desarrollar la cartera de servicios de las asociaciones, incorporando entre los mismos la función de orientación sociolaboral. En el artículo, también se presenta la propuesta de intervención que surgió a raíz del estudio empírico.

\section{Estado de la cuestión}

La violencia de género es un problema prioritario de salud pública (Organización Mundial de la Salud, 2013) y un problema social que entraña preocupación por los efectos que alcanzan a generar sobre la persona que la padece (Martos et al., 2016). El Ministerio de Sanidad, Servicios Sociales e Igualdad (2017) indica que la violencia de género es un fenómeno que durante décadas no se ha hecho lo suficientemente visible, sin embargo, implica una manifestación clara de la desigualdad y la subordinación que sufre la mujer. Ortiz (2013) además señala a la violencia de género como un fenómeno socio-jurídico, ya que además de vulnerar a la víctima física, psicológica y socialmente, lo hace en tanto a su vulneración de los derechos como ser humano. Por ello Expósito (2011) entiende esa problemática como un binomio de dos variables, la violencia y el género, implicando una conducta donde se evidencia la desigualdad en la relación interpersonal que se produce, empleándose como medio la violencia para lograr mayor poder con respecto a la mujer.

Sin embargo, este tipo de violencia no depende de manera exclusiva del hombre que ejerce fuerza y violencia contra la mujer por razón de sexo, sino que esta violencia encuentra su foco en la estructura social patriarcal, y es ahí donde las relaciones que se producen y los roles sociales que se generan pueden explicar la relación social de poder del hombre sobre la mujer (Guerra, 2014; Hunnicutt, 2009). 


\begin{tabular}{|c|c|}
\hline $\begin{array}{l}\text { Revista } \\
\text { Latina } \\
\text { de Sociologia }\end{array}$ & $\begin{array}{l}\text { Revista Latina de Sociología (RELASO) } \\
\text { Vol. 9, núm. } 2 \text { (2019), pp. 24-58 } \\
\text { ISSN-e 2253-6469 } \\
\text { DOI: https://doi.org/10.17979/relaso.2019.9.2.6826 }\end{array}$ \\
\hline
\end{tabular}

De acuerdo con la Organización Mundial de la Salud (2017) alrededor de una de cada tres (35\%) mujeres en el mundo han sufrido violencia física y/o sexual de pareja o violencia sexual por terceros en algún momento de su vida; la mayoría de estos casos son violencia infligida por la pareja. Además, en todo el mundo, casi un tercio (30\%) de las mujeres que han tenido una relación de pareja refieren haber sufrido alguna forma de violencia física y/o sexual por parte de su pareja en algún momento de su vida. Y un 38\% de los asesinatos de mujeres que se producen en el mundo son cometidos por su pareja masculina.

Acompañando a estos datos, podemos identificar el porcentaje de la población femenina que ha sufrido tanto en España como en la Unión Europea violencia a lo largo de su vida, o en el último año (Tabla 1). Estos datos son extraídos de la Macroencuesta que el Ministerio de Sanidad, Servicios Sociales e Igualdad (2015) llevó a cabo.

Tabla 1. Datos de la Macroencuesta del Ministerio de Sanidad, Servicios Sociales e Igualdad (2015).

\begin{tabular}{|c|c|c|}
\hline & España & Unión Europea \\
\hline A lo largo de la vida & $\begin{array}{l}\text { - Violencia física } 10,3 \% \\
\text { - Violencia sexual 8,1\% } \\
\text { - Violencia psicológica de } \\
\text { - Vontrol 25,4\% } \\
\text { - } \text { - Violencia psicológica } \\
\text { - } 10,8 \%\end{array}$ & $\begin{array}{l}\text { - Violencia física } 20 \% \\
\text { - Violencia sexual } 7 \% \\
\text { - Violencia psicológica } \\
\text { de control 35\% } \\
\text { - Violencia psicológica } \\
\text { emocional 32\% } \\
\text { - Violencia económica } \\
12 \%\end{array}$ \\
\hline Últimos de 12 meses & $\begin{array}{l}\text { - Violencia física 1,8\% } \\
\text { - Violencia sexual } 1,4 \%\end{array}$ & $\begin{array}{l}\text { - Violencia física 4\% } \\
\text { • Violencia sexual 1\% }\end{array}$ \\
\hline
\end{tabular}

Fuente: elaboración propia. 


\section{Revista \\ Latina \\ de Sociologia}

Revista Latina de Sociología (RELASO)

Vol. 9, núm. 2 (2019), pp. 24-58

ISSN-e 2253-6469

DOI: https://doi.org/10.17979/relaso.2019.9.2.6826

Por su parte, la Delegación del Gobierno para la Violencia de Género (2019) emite de forma actualizada las cifras oficiales en materia de violencia de género en España. Los datos que se presentan son del año 2010 al año 2019 en España, en relación con las denuncias por violencia de género, las mujeres perceptoras de la Renta Activa de Inserción (prestación destinada a las víctimas de esta violencia), cifra de mujeres víctimas asesinadas y cifra de menores víctimas asesinados y la cifra de contratos bonificados (Tabla 2). Pese a que en el estudio se han recogido las cifras de los últimos diez años, la Delegación del Gobierno para la Violencia de Género (2019) desde el año 2003 registra y actualiza oficialmente las cifras, a excepción de las cifras de los menores que han sido víctimas mortales, de los cuales se comienza a tener referencia en el conteo del año 2013.

Tabla 2. Cifras desde el 2010 hasta el 2019 actualizadas por la Delegación del Gobierno para la Violencia de Género (2019).

\begin{tabular}{lcccccc}
\hline & $\begin{array}{l}\text { Llamadas } \\
\text { violencia } \\
\text { de género }\end{array}$ & $\begin{array}{l}\text { Denuncias } \\
\text { violencia de } \\
\text { género }\end{array}$ & $\begin{array}{l}\text { Perceptoras } \\
\text { Renta Activa } \\
\text { de Inserción }\end{array}$ & $\begin{array}{l}\text { Mujeres } \\
\text { víctimas } \\
\text { mortales }\end{array}$ & $\begin{array}{c}\text { Menores } \\
\text { víctimas } \\
\text { mortales }\end{array}$ & $\begin{array}{c}\text { Contratos } \\
\text { bonificados }\end{array}$ \\
\hline $\mathbf{2 0 1 0}$ & 67696 & 134105 & 25512 & 73 & - & 395 \\
\hline $\mathbf{2 0 1 1}$ & 70679 & 134002 & 29065 & 62 & - & 464 \\
\hline $\mathbf{2 0 1 2}$ & 55810 & 128477 & 30065 & 51 & - & 459 \\
\hline $\mathbf{2 0 1 3}$ & 58274 & 124893 & 32596 & 54 & 42 & 626 \\
\hline $\mathbf{2 0 1 4}$ & 68851 & 126742 & 34550 & 55 & 43 & 725 \\
\hline $\mathbf{2 0 1 5}$ & 81992 & 129193 & 34695 & 60 & 51 & 836 \\
\hline $\mathbf{2 0 1 6}$ & 85318 & 143535 & 33565 & 49 & 30 & 801 \\
\hline $\mathbf{2 0 1 7}$ & 77796 & 166260 & 31398 & 50 & 25 & 808 \\
\hline $\mathbf{2 0 1 8}$ & 73454 & 166961 & 29802 & 51 & 41 & 1075 \\
\hline $\mathbf{2 0 1 9}$ & 63081 & 125936 & 26335 & 55 & 46 & 836 \\
\hline
\end{tabular}

Fuente: elaboración propia.

Rev.Lat.Soc. Vol. 9(1) (2019) pp. 24-58. ISSN-e 2253-6469 


\section{Revista \\ Latina \\ de Sociologia}

Revista Latina de Sociología (RELASO)

Vol. 9, núm. 2 (2019), pp. 24-58

ISSN-e 2253-6469

DOI: https://doi.org/10.17979/relaso.2019.9.2.6826

Si bien la evolución de las cifras permite visualizar que tanto el número de llamadas por violencia de género, el número de denuncias, el número de perceptoras de la Renta Activa de Inserción, así como el número de víctimas mortales han tenido una tendencia al descenso, se mantiene estable la realidad de la violencia de género en el país. Un dato importante para analizar es el de los contratos bonificados que se conceden a las mujeres víctimas de violencia de género, como medida para potenciar sus posibilidades de empoderamiento económico y fomentar la opción de salir del hogar donde se produce la relación de maltrato.

Además de estos datos, en el año 2005 la Organización Mundial de la Salud realizó un estudio donde se comprobaba que entre el 15\% en Japón hasta el 79\% en Perú de las mujeres con edades comprendidas entre 15 y 49 años habían sufrido violencia física y/o sexual por parte de su pareja en algún momento de su vida (Puente-Martínez et al., 2016).

Por todo ello resulta necesario favorecer el empoderamiento de la mujer también a nivel económico. La independencia económica potencia las oportunidades de romper las relaciones de dependencia financiera y logra romper las relaciones de maltrato que se producen. No obstante, la mujer en el mercado laboral también ha contado con desigualdades a las que ha debido enfrentarse. En relación con la incorporación de la mujer al mercado laboral, Lorente \& Lorente (1998) exponen que la incorporación de la mujer al ámbito laboral y a la esfera social ha generado, en ocasiones, la inversión de los roles, teniendo el hombre que unirse a las tareas que hasta entonces socialmente se consideraba cometido de las mujeres. Esta situación ha generado tensiones, y en según qué casos, socialmente para el hombre podría suponer una pérdida de poder, lo cual podría implicar sentimientos de agresividad, que derivaría en violencia. Las causas principales de esta violencia son el contexto social y la cultura, junto al constructo que se ha generado para perpetuar este tipo de violencia, utilizando así, la vulnerabilidad psicológica, entre otras (Wardetrudis, 2015). Además, existe una gran brecha de género en el mercado laboral, que repercute sobre las mujeres con salarios inferiores frente a las ganancias de los hombres y el índice del trabajo precario es superior para ellas frente a ellos (Subirats et al., 2004).

Como señalan Laparra et al. (2007) hay personas que tienen un puesto de trabajo, sin embargo, este es precario debido a que no satisface sus necesidades. Esto lleva a que haya un porcentaje de personas que no superan el umbral de la pobreza. Este aspecto que lleva un tiempo siendo estudiado y analizado en España, ya empezó a estudiarse con anterioridad en otros países como Estados Unidos. Dos colectivos con vulnerabilidad ante la precariedad son los jóvenes y las mujeres (Laparra et al., 2007). Y es que, conforme a Vicente \& Martínez (2010), la mujer como conjunto, como colectivo, ha sido a lo largo de la historia un grupo de riesgo de exclusión social y en situación de exclusión social. 


\begin{tabular}{|l|l|l|}
\hline Revista & & $\begin{array}{l}\text { Revista Latina de Sociologia (RELASO) } \\
\text { Vol. 9, núm. 2 (2019), pp. 24-58 } \\
\text { ISSN-e 2253-6469 } \\
\text { Datina }\end{array}$ \\
de Sociologs://doi.org/10.17979/relaso.2019.9.2.6826 & \\
\hline
\end{tabular}

Algunas cifras que identifican esta problemática son las que se pueden visualizar en las Figuras 1 y 2.

Figura 1. Desempleo en España en 2019, desagregados por sexo

\begin{tabular}{|r|c|c|c|}
\hline & \multicolumn{3}{|c|}{ España: Parados 2019} \\
\hline & Parados & Parados hombres & Parados mujeres \\
\hline Septiembre 2019 & $3.214 \mathrm{~m}$. & $1.500,5 \mathrm{~m}$. & $1.713,9 \mathrm{~m}$. \\
\hline Junio 2019 & $3.231 \mathrm{~m}$. & $1.534,1 \mathrm{~m}$. & $1.696,5 \mathrm{~m}$. \\
\hline Marzo 2019 & $3.354 \mathrm{~m}$. & $1.570,5 \mathrm{~m}$. & $1.783,8 \mathrm{~m}$. \\
\hline Diciembre 2018 & $3.304 \mathrm{~m}$. & $1.574,1 \mathrm{~m}$. & $1.730,2 \mathrm{~m}$. \\
\hline < Parados 2018 & & & \\
\hline
\end{tabular}

Fuente: Datosmacro (2020). 


\section{Revista \\ Latina \\ de Sociologia}

Revista Latina de Sociología (RELASO)

Vol. 9, núm. 2 (2019), pp. 24-58

ISSN-e 2253-6469

DOI: https://doi.org/10.17979/relaso.2019.9.2.6826

Figura 2. Desempleo en España en septiembre de 2019, desagregados por sexo y comunidades autónomas

\begin{tabular}{|c|c|c|c|}
\hline \multicolumn{4}{|c|}{ Tasa de desempleo (EPA): Por sexo } \\
\hline CCAA & Tasa de desempleo hombres & Tasa de desempleo mujeres & Mes \\
\hline Andalucía [+] & $18,4 \%$ & $26,0 \%$ & Septiembre 2019 \\
\hline Aragón [+] & $8,7 \%$ & $10,9 \%$ & Septiembre 2019 \\
\hline Asturias $[+]$ & $14,2 \%$ & $14,7 \%$ & Septiembre 2019 \\
\hline Cantabria [+] & $8,1 \%$ & $9,4 \%$ & Septiembre 2019 \\
\hline Ceuta $[+]$ & $26,1 \%$ & $32,5 \%$ & Septiembre 2019 \\
\hline Castilla y León [+] & $9,7 \%$ & $13,0 \%$ & Septiembre 2019 \\
\hline Castilla La Mancha [+] & $12,3 \%$ & $21,0 \%$ & Septiembre 2019 \\
\hline Canarias [+] & $18,8 \%$ & $24,0 \%$ & Septiembre 2019 \\
\hline Cataluña [+] & $10,3 \%$ & $11,5 \%$ & Septiembre 2019 \\
\hline Extremadura $[+]$ & $15,3 \%$ & $25,1 \%$ & Septiembre 2019 \\
\hline Galicia [+] & $9,8 \%$ & $13,3 \%$ & Septiembre 2019 \\
\hline Islas Baleares [+] & $8,0 \%$ & $8,4 \%$ & Septiembre 2019 \\
\hline Murcia [+] & $12,2 \%$ & $16,6 \%$ & Septiembre 2019 \\
\hline Madrid [+] & $9,4 \%$ & $11,2 \%$ & Septiembre 2019 \\
\hline Melilla [+] & $22,4 \%$ & $36,8 \%$ & Septiembre 2019 \\
\hline Navarra $[+]$ & $6,6 \%$ & $10,0 \%$ & Septiembre 2019 \\
\hline País Vasco $[+]$ & $8,3 \%$ & $10,3 \%$ & Septiembre 2019 \\
\hline La Rioja [+] & $9,8 \%$ & $8,1 \% \square$ & Septiembre 2019 \\
\hline Comunidad Valenciana $[+]$ & $11,4 \%$ & $16,8 \%$ & Septiembre 2019 \\
\hline
\end{tabular}

Fuente: Datosmacro (2020).

Tal y como se observa en las dos figuras las mujeres son más afectadas por la situación de desempleo. Desde diciembre de 2018 hasta la actualidad ha habido mayor número de mujeres desempleadas en España que hombres, y esta es una realidad que se ha mantenido a lo largo de los años (Instituto Nacional de Estadística, 2019). Además, llevando a cabo el balance en relación con las Comunidades Autónomas, en todas ellas, a excepción de La Rioja, las mujeres presentan mayores índices de desempleo que los hombres, en algunos casos hasta superando diez puntos más para las mujeres que para los hombres. 


\begin{tabular}{|l|l|l|}
\hline Revista & & $\begin{array}{l}\text { Revista Latina de Sociologia (RELASO) } \\
\text { Vol. 9, núm. 2 (2019), pp. 24-58 } \\
\text { ISSN-e 2253-6469 } \\
\text { Dor: https://doi.org/10.17979/relaso.2019.9.2.6826 }\end{array}$ \\
de Sociologia & &
\end{tabular}

\section{Estudio empírico}

Debido a la influencia que el desempleo tiene sobre la mujer y especialmente cuando se trata de situaciones de doble discriminación (López, 2017), donde no solo existe la causa de ser mujer si no también la comorbilidad por pertenecer a un colectivo en riesgo de exclusión social, se ha llevado a cabo un estudio empírico.

La investigación se llevó a cabo durante el 2017 en entidades del Tercer Sector que trabajan con mujeres en situación de exclusión social, siendo la principal casuística de la exclusión social, la violencia de género. Además, las mujeres atendidas por estas entidades presentaban situación de desempleo en la mayoría de los casos.

Como se expondrá posteriormente, el 75\% de las mujeres atendidas por las asociaciones no tenían estudios superiores, ni puesto de trabajo, no obstante, sí tenían familiares a cargo. Así pues, presentan necesidades económicas, en primer lugar, por la relación de maltrato mantenida con la pareja o expareja y, en segundo lugar, por la necesidad de responder a las necesidades familiares.

La investigación permitió presentar el perfil de mujer atendida por las entidades participantes, así como identificar las tareas de orientación sociolaboral ejercidas por las asociaciones y todo ello permitió el planteamiento de la propuesta.

En el presente estudio y la derivada intervención planteada se destaca el papel de la orientación sociolaboral (García, 2019; Izquierdo \& Farías, 2018; Sevillano, 2017; VerdugoCastro, 2019), como canal para guiar a las mujeres atendidas en relación con sus habilidades sociales, laborales, y ofrecerlas recursos de búsqueda activa de empleo, entre ellos, el manejo de las nuevas tecnologías e Internet. Además, la orientación sociolaboral está dirigida a la elaboración del currículum, cartas de presentación, cartas de motivación. También guía para emprender en la posibilidad del autoempleo, y genera oportunidades a través de la intermediación laboral entre empresas. El seguimiento de una persona cualificada durante el proceso de búsqueda de empleo y el mantenimiento del puesto, ofrece un apoyo a la persona. El fin último de la orientación sociolaboral es que la persona alcance un puesto laboral estable, que favorezca a la mejora y empoderamiento integral de la persona para solventar la situación problema.

\section{Objetivos de la investigación}

El objetivo general de la investigación es plantear una propuesta de intervención basada en la orientación sociolaboral, adecuada a las necesidades específicas de las destinatarias de las asociaciones participantes en el estudio. 


\begin{tabular}{|l|l|l|}
\hline Revista & & $\begin{array}{l}\text { Revista Latina de Sociologia (RELASO) } \\
\text { Vol. 9, núm. 2 (2019), pp. 24-58 } \\
\text { ISSN-e 2253-6469 } \\
\text { Datina }\end{array}$ \\
de Sociologs://doi.org/10.17979/relaso.2019.9.2.6826 & \\
\hline
\end{tabular}

Para alcanzar dicho objetivo general se plantean como objetivos específicos:

- Definir el perfil laboral, formativo y familiar de las mujeres atendidas en las asociaciones.

- Averiguar las acciones de orientación sociolaboral por parte de las entidades participantes.

\section{Pregunta de investigación}

La pregunta de investigación a la que se ha dado respuesta es: ¿Qué relevancia implica la orientación sociolaboral en relación con el empoderamiento integral de la mujer víctima de violencia de género?

\section{Participantes}

En colaboración con el tejido social de la provincia del estudio, se llevó a cabo una revisión sobre las entidades del Tercer Sector que cumplían los criterios de inclusión planteados para la investigación: entidades del Tercer Sector de la provincia de Valladolid (España), que trabajasen con mujeres en situación de exclusión social, con casuística de violencia de género y de desempleo. Finalmente, y tras esta revisión, se invitaron a las entidades que cumplían los criterios, y participaron finalmente en el estudio nueve asociaciones.

En relación con el perfil de mujer atendida desde las asociaciones participantes: la asociación 1 (de aquí en adelante, P.1) trabaja con víctimas de agresiones sexuales y malos tratos, la P.2 y la P.3 trabajan con mujeres trabajadoras del sexo, la P.4 con mujeres en situación de desempleo y con casuística de violencia de género, la P.5 al igual que la P.7 trabajan con un perfil heterogéneo, con multicausalidad de exclusión y un índice de desempleo en el 70\% de los casos asistidos. La P.6 se dirige a mujeres en situación de desempleo, al igual que la P.9, aunque esta última se centra en el colectivo inmigrante. Y la P.8 se focaliza en la atención de mujeres víctimas de violencia de género, consumidoras de sustancias y en situación de desempleo.

\section{Metodología y método}

El foco del estudio empírico ha sido averiguar el perfil de mujer atendida por parte de las asociaciones, así como las tareas de orientación sociolaboral llevadas a cabo desde las mismas. Para este último punto, el interés ha recaído en el discurso de las personas que trabajan en las entidades.

Se ha llevado a cabo la parte empírica a través del enfoque cualitativo, y mediante el método fenomenológico (Anguera, 1999; Delgado et al., 2007; Sánchez, 2015), ya que las entrevistas semiestructuradas se han centrado en la experiencia de las trabajadoras y la 


\section{Revista \\ Latina \\ de Sociologia}

Revista Latina de Sociología (RELASO)

Vol. 9, núm. 2 (2019), pp. 24-58

ISSN-e 2253-6469

DOI: https://doi.org/10.17979/relaso.2019.9.2.6826

realidad de las entidades. Añadido a esto, de los discursos recopilados ha surgido la propuesta de intervención, adecuada a la realidad de la investigación. El enfoque cualitativo de la investigación coincide con el seguido en la investigación de Verdugo-Castro et al. (2019).

Las dimensiones que han sido abordadas cursaban entorno al perfil socioeconómico, formativo y familiar de las destinatarias. Interesándose la investigación por la causa de exclusión social, su nivel de formación, experiencia laboral, familiares a cargo. Además, estas dimensiones también cursaban entorno a las líneas de actuación de las entidades, principalmente, la tarea de orientación laboral, y el perfil profesional. El sistema de categorías sobre el que se ha trabajado es el que se presenta en la Tabla 3.

Tabla 3. Categorías estudiadas

\begin{tabular}{|l|l|}
\hline Líneas de trabajo & $\begin{array}{l}\text { La categoría hace referencia al eje central de atención de cada entidad. } \\
\text { Las principales líneas de las asociaciones son las relativas a: la } \\
\text { atención de las necesidades básicas, el entrenamiento de habilidades } \\
\text { (laborales, sociales, y de motivación), la asistencia jurídica, la } \\
\text { orientación sociolaboral, la asistencia psicológica, y la realización de } \\
\text { talleres sociolaborales y preocupacionales. }\end{array}$ \\
\hline Perfil de la entidad & $\begin{array}{l}\text { La categoría del perfil de la entidad responde a la plantilla con la que } \\
\text { se dispone: personal sanitario, figuras de abogado, psicólogo, y } \\
\text { figuras sociales: educador social, trabajador social y orientador } \\
\text { sociolaboral. }\end{array}$ \\
\hline $\begin{array}{l}\text { Sinergias } \\
\text { interdisciplinariedad }\end{array}$ & $\begin{array}{l}\text { La mencionada categoría tiene que ver con la coordinación y la } \\
\text { colaboración que se presta con otros recursos comunitarios. }\end{array}$ \\
\hline $\begin{array}{l}\text { Situación } \\
\text { exclusión social }\end{array}$ & $\begin{array}{l}\text { Las causas de exclusión social pueden ser: el desempleo, violencia de } \\
\text { género, prostitución, consumo de sustancias e inmigración. }\end{array}$ \\
\hline
\end{tabular}

Fuente: elaboración propia.

En relación con la orientación sociolaboral destacan las tareas de: formación prelaboral y ocupacional, intermediación entre empresas, Itinerarios Individualizados para la inserción laboral, orientación para el emprendimiento y autoempleo y tutorías de seguimiento individualizadas.

\section{Técnicas de recogida de información}

La técnica que se empleó para el proceso de recogida de información fue la entrevista semiestructurada, para así alcanzar a conocer los estudios de caso, siendo cada uno de ellos

Rev.Lat.Soc. Vol. 9(1) (2019) pp. 24-58. ISSN-e 2253-6469 


\begin{tabular}{|l|l|l|}
\hline Revista & & $\begin{array}{l}\text { Revista Latina de Sociologia (RELASO) } \\
\text { Vol. 9, núm. 2 (2019), pp. 24-58 } \\
\text { ISSN-e 2253-6469 } \\
\text { DoI: https://doi.org/10.17979/relaso.2019.9.2.6826 }\end{array}$ \\
de Sociologia & &
\end{tabular}

una de las nueve entidades participantes. Las entrevistas semiestructuradas fueron dispensadas a cinco trabajadoras de las entidades, en su mayoría psicólogas, trabajadoras sociales o educadoras sociales. Al llevar a cabo las entrevistas se garantizó el anonimato y la confidencialidad de la información. Se seleccionaron a las cinco trabajadoras participantes por su trayectoria en las entidades, el conocimiento de las líneas de actuación y sus servicios prestados mediante sinergias en más de una entidad, como es el caso de las sinergias mantenidas entre las P.1, P.2 y P.3, donde algunas de las intervenciones aplicadas se hacen de forma conjunta y simultánea; por ejemplo, seguimiento continuado de una persona en dos entidades, porque en cada una recibe un servicio diferente (psicológico por un lado y laboral/social por otro). Otros casos de sinergia entre entidades y profesionales son la mantenida entre la P.1, P.4 y la P.6; y entre la P.4 y la P.8. Además de las entrevistas semiestructuradas, se recogió información de corte cualitativo de informes anuales facilitados para el fin de la investigación.

Las entrevistas semiestructuradas profundizaron en las causas de exclusión social y el perfil de su colectivo atendido, las líneas de trabajo desarrolladas por parte de la entidad y el perfil profesional de la entidad.

Las entrevistas semiestructuradas aplicadas seguían el sentido lógico de las categorías que se plantearon para el desarrollo de la investigación (Tabla 3), respetando así el proceso de categorización (Delgado-Álvarez et al., 2012) que se desarrolló tras la transcripción de las entrevistas. Dicha transcripción respetó la literalidad de los discursos. Para la interpretación de los discursos se codificó la información conforme al sistema de nodos que se creó.

\section{Análisis de datos}

El análisis de datos fue clásico de contenido (Andréu, 2000) y se llevó a cabo mediante el CAQDAS Nvivo 12 de análisis cualitativo. A partir del software de análisis se pudo analizar los discursos, así como la exportación de outputs visuales, como conglomerados de relación, dendrogramas, nubes de palabras o mapas mental, conceptual y de proyecto.

En la Figura 3 se puede observar la relación que se establece entre los casos analizados desde Nvivo12 por cada entidad con los documentos importados a la base de datos y analizados, en función de la similitud del contenido. Además, la relación nace de dos nodos principales del sistema de nodos (categorías de análisis), que son las líneas de trabajo de las entidades con la situación de exclusión social de las mujeres atendidas.

Figura 3. Conglomerado de relación entre dos nodos principales de análisis, casos de estudio y fuentes de información importadas 


\begin{tabular}{|l|l|l|}
\hline Revista & & $\begin{array}{l}\text { Revista Latina de Sociología (RELASO) } \\
\text { Vol. 9, núm. 2 (2019), pp. 24-58 } \\
\text { ISSN-e 2253-6469 } \\
\text { Dotin https://doi.org/10.17979/relaso.2019.9.2.6826 }\end{array}$ \\
\hline de Sociologia & &
\end{tabular}

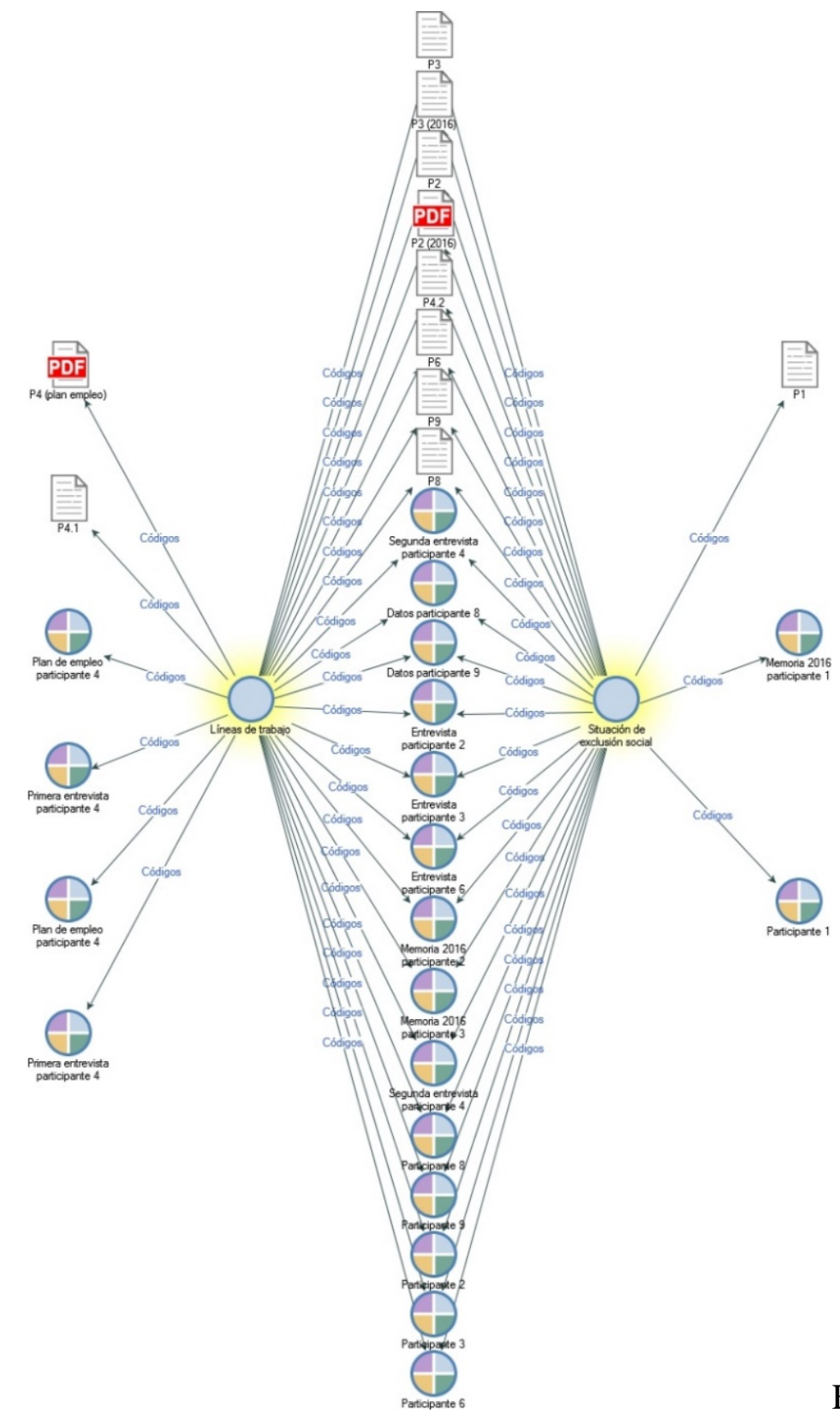

Fuente: elaboración propia a partir de Nvivo12.

Por su parte, en la Figura 4 se puede observar la relación mantenida entre el sistema de nodos generado y las fuentes de información, con respecto al contenido codificado.

Figura 4. Conglomerado entre el sistema de nodos y las fuentes de información con contenido codificado. 


\begin{tabular}{|l|l|l|}
\hline Revista & & $\begin{array}{l}\text { Revista Latina de Sociología (RELASO) } \\
\text { Vol. 9, núm. 2 (2019), pp. 24-58 } \\
\text { ISSN-e 2253-6469 } \\
\text { Dotin https://doi.org/10.17979/relaso.2019.9.2.6826 }\end{array}$ \\
\hline de Sociologia & &
\end{tabular}

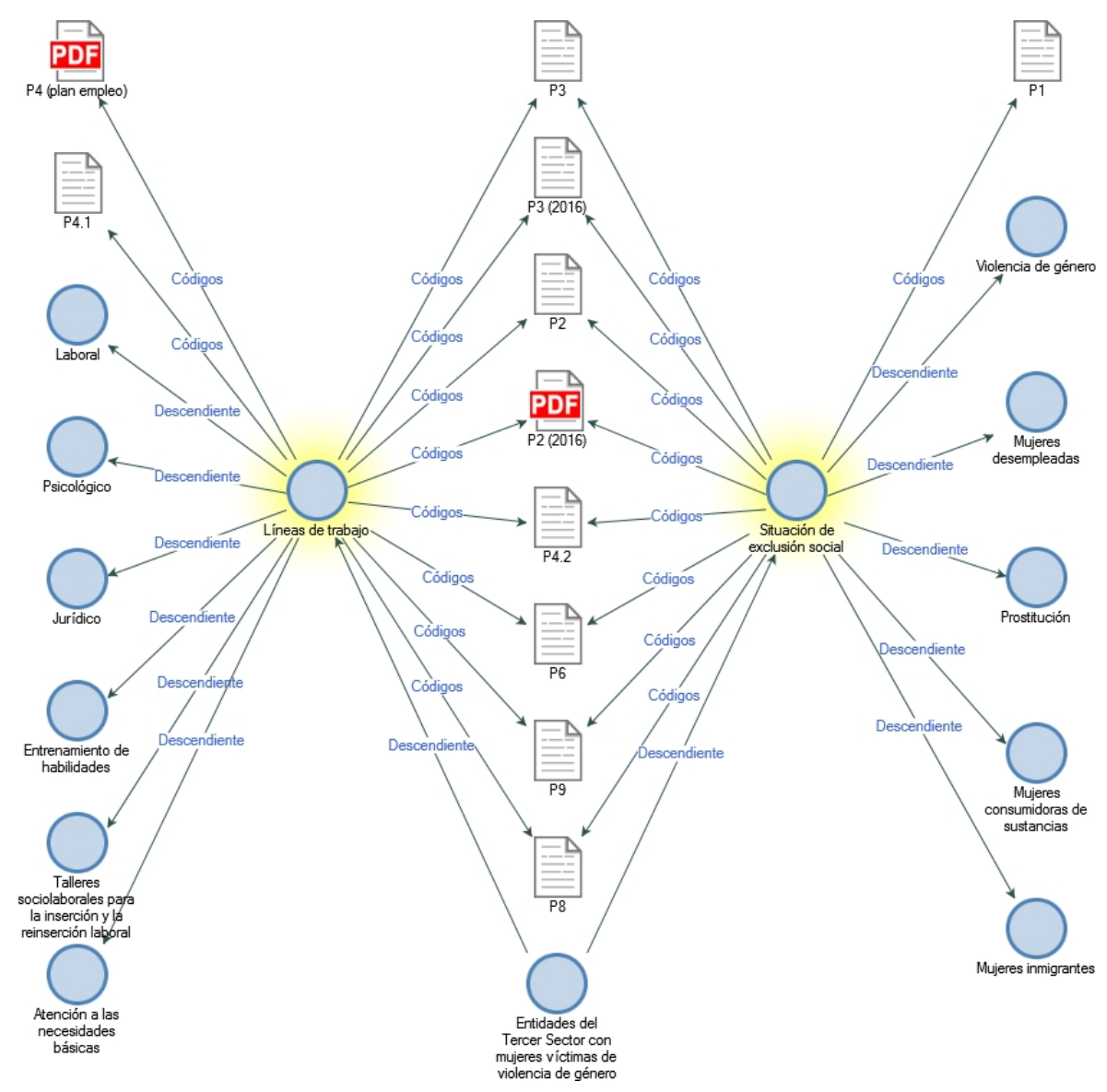

Fuente: elaboración propia a partir de Nvivo12.

\section{Resultados del estudio empírico}

Tras el análisis de las entrevistas semiestructuras se pudo definir el perfil predominante de las mujeres atendidas por las entidades. Son mujeres de una edad cercana a los 40 años, principalmente de nacionalidad española, habitantes de la provincia del estudio, en situación de desempleo y víctimas de violencia de género, con familiares a su cargo y en el 75\% de los casos de bajo nivel formativo.

Además, en cuanto a las tareas sociolaborales desarrolladas por las entidades, algunas de ellas como P.1, P.5 y P.7 no disponían de línea de orientación sociolaboral por falta de recursos humanos específicos, o carencia de recursos de otra índole como económicos, o espacio-temporales. P.9 sí desarrollaba puntualmente alguna tarea de orientación sociolaboral. No obstante, las principales asociaciones con servicio de orientación sociolaboral eran P.2, P.3, P.4, P.6 y P.8. Y así se ha recogido en sus discursos. En la Tabla 4 se recogen contenidos sustanciales del discurso de las entidades, en respuesta a las tareas que se ejercen desde las asociaciones. 


\section{Revista \\ Latina \\ de Sociologia}

Revista Latina de Sociología (RELASO)

Vol. 9, núm. 2 (2019), pp. 24-58

ISSN-e 2253-6469

DOI: https://doi.org/10.17979/relaso.2019.9.2.6826

Tabla 4. Discurso recogido en las entrevistas semiestructuradas a las cinco trabajadoras de las entidades.

\begin{tabular}{|c|c|}
\hline Entidad & SCl \\
\hline P.2 & $\begin{array}{l}\text { "Nosotros tenemos aquí talleres preocupacionales, sobretodo. Pero también } \\
\text { orientados un poquito a que les faciliten la inserción laboral." } \\
\text { "Hemos realizado talleres como: el profesional, motivación profesional, } \\
\text { satisfacción, habilidades socioprofesionales.” } \\
\text { "En P.2 hay una educadora social, una trabajadora social, y la psicóloga y luego } \\
\text { tenemos a la directora que es psicopedagoga, quien realiza las funciones de } \\
\text { dirección. Nosotras, la educadora social, la trabajadora social y yo, la psicóloga, } \\
\text { nos dedicamos a realizar la atención individualizada.” }\end{array}$ \\
\hline P.3 & $\begin{array}{l}\text { "Se plantean Itinerarios de inserción, sobre todo se trabaja la motivación. } \\
\text { Desde P.3 se ayuda a los usuarios a la elaboración de currículums, y al aprendizaje } \\
\text { del uso del ordenador.” } \\
\text { "Se les abre un correo electrónico y se les enseña el manejo del mismo y de } \\
\text { Internet para realizar una búsqueda activa de empleo.” } \\
\text { "A nivel sociolaboral, quien establece el diagnóstico son el educador y el } \\
\text { trabajador social. Y a partir del diagnóstico de la situación se plantea el Itinerario.” }\end{array}$ \\
\hline P.4 & $\begin{array}{l}\text { “Los profesionales que trabajan en el ámbito de la inserción laboral: } \\
\text { orientadoras laborales y una perceptora de busca de empleo.” } \\
\text { "Son Itinerarios intensificados.” } \\
\text { "Desde P.4 se trabaja con ellos para hacer y mejorar el currículum y preparar } \\
\text { la entrevista. Dentro de la orientación grupal se hacen simulaciones de entrevistas } \\
\text { por competencias. De tal modo que se intenta que todo el trabajo sea práctico y } \\
\text { dinámico.” } \\
\text { "Sí, se hace una orientación individual, grupal, se hace intermediación y } \\
\text { acompañamiento y seguimiento a lo largo del proceso.” }\end{array}$ \\
\hline P.6 & $\begin{array}{l}\text { "Aquí hay educadores sociales, trabajadores sociales, licenciadas en Derecho } \\
\text { profesoras.” }\end{array}$ \\
\hline
\end{tabular}




\begin{tabular}{|l|l|l|}
\hline Revista & $\begin{array}{l}\text { Revista Latina de Sociología (RELASO) } \\
\text { Vol. 9, núm. 2 (2019), pp. 24-58 } \\
\text { ISSN-e 2253-6469 } \\
\text { Dot: https://doi.org/10.17979/relaso.2019.9.2.6826 }\end{array}$ \\
\hline
\end{tabular}

\begin{tabular}{|l|l|}
\hline & $\begin{array}{l}\text { "Trabajamos con ellos las competencias transversales, el autoconocimiento, } \\
\text { resolución de conflictos, cómo comportarse en una entrevista de trabajo, cómo } \\
\text { defender tu currículum. Y luego, se trabaja sobre todo el tema de las nuevas } \\
\text { tecnologías. Concretamente aquí sobre todo lo que hacemos es intermediación } \\
\text { tanto con empresas como con familias.” }\end{array}$ \\
\hline $\mathbf{P . 8}$ & $\begin{array}{l}\text { "La reinserción se trabaja a través de formación, continuando los estudios, y } \\
\text { haciendo búsqueda activa de empleo, dependiendo de su nivel de inserción que } \\
\text { puede de mayor o de menos intensidad. [...] El Plan Individualizado se ajusta } \\
\text { inicia por la demanda que sea, llevándose a cabo un diagnóstico.” } \\
\text { "En este tipo de tratamiento hay trabajadores sociales, orientadores } \\
\text { sociolaborales, psicólogos, abogados y psiquiatras.” }\end{array}$ \\
\hline
\end{tabular}

Fuente: elaboración propia.

Algunos de los principales resultados que se obtienen de la aproximación empírica es en primer lugar, la necesidad de ampliar la oferta de orientación sociolaboral por parte de las asociaciones, debido a las necesidades y demandas que presentan las mujeres atendidas por parte de estas. Como se comentaba anteriormente, se trata de un perfil de baja cualificación, y sin estudios superiores en el 75\%, además, tal y como transmiten las personas entrevistadas, demandan formación en acceso a nuevas tecnologías por su bajo grado de competencia digital.

Es por ello por lo que en la propuesta planteada se incide en la formación, especialmente, así como en el trabajo desde dispositivos digitales y nuevas tecnologías. Por otro lado, en la propuesta se tienen en cuenta elementos como la familia y el entorno social, por lo que también es necesario trabajar las habilidades laborales y sociales.

\section{Propuesta de intervención}

La propuesta de intervención se asienta sobre el Modelo de Atención “Objetivo Violencia Cero” de la Junta de Castilla y León (2015).

De acuerdo con las directrices de funcionamiento en Castilla y León del Modelo de Atención Integral a las víctimas de Violencia de Género (2015), “el Estatuto de Autonomía de Castilla y León, en el apartado 1 de su artículo 14 prohíbe expresamente la discriminación de género, y en el apartado 2 exige a los poderes públicos de la Comunidad garantizar la transversalidad del principio de igualdad de género en todas sus políticas, promoviendo acciones positivas para lograr la igualdad de oportunidades entre mujeres y 


\begin{tabular}{|l|l|l|}
\hline Revista & & $\begin{array}{l}\text { Revista Latina de Sociologia (RELASO) } \\
\text { Vol. 9, núm. 2 (2019), pp. 24-58 } \\
\text { ISSN-e 2253-6469 } \\
\text { Dor: https://doi.org/10.17979/relaso.2019.9.2.6826 }\end{array}$ \\
de Sociologia & &
\end{tabular}

hombres y dedicando mayor apoyo a los colectivos de mujeres en situación de necesidad especial, particularmente las víctimas de violencia de género".

Dicho modelo está diseñado para que sean agentes y colaboradores del modelo de atención, acogiéndose a sus fines, objetivos, principios rectores y directrices, tanto las Administraciones Públicas de Castilla y León, agentes del sistema de servicios sociales de responsabilidad pública, administraciones, organismos y entidades públicas, Fuerzas y Cuerpos de Seguridad del Estado, órganos judiciales, Ministerio Fiscal, Universidades, y entidades privadas que tengan entre sus fines la atención a las víctimas de violencia de género que desarrollen alguna de las prestaciones que se recogen en el catálogo de servicios sociales de Castilla y León aprobado por Decreto 58/2014, de 11 de diciembre.

Bajo este amparo se diseña una propuesta de intervención, pensada para un grupo de mujeres con el perfil señalado. Se trata de una intervención pensada para un grupo de veinticinco personas.

\section{Objetivo de la intervención}

La misión última que se persigue alcanzar con la siguiente propuesta de intervención es favorecer el alcance de la autonomía económica y psicológica y el empoderamiento de las mujeres víctimas de violencia de género, destinatarias de la propuesta. Para lograr la autonomía se propone trabajar las habilidades de búsqueda activa y próspera de empleo, y el establecimiento de relaciones sociales saludables. En la presente propuesta de intervención, la orientación para el empleo y la formación es el canal para el alcance de dicha misión.

Los objetivos de la intervención son:

- Fomentar la mejora de la situación biopsicosocial de las destinatarias de la intervención.

- Trabajar con las destinatarias las habilidades sociales y laborales.

- Incentivar las acciones formativas para las beneficiarias de la intervención.

- Acentuar los esfuerzos en la orientación laboral.

- Enseñar adecuadas estrategias de búsqueda activa de empleo.

\section{Destinatarias de la propuesta}

La propuesta de intervención está diseñada para veinticinco mujeres, que cumplen con el perfil que se ha descrito en el trabajo presentado. Para participar en la propuesta son necesarias tres condiciones: estar en situación de desempleo, estar en proceso de búsqueda de empleo y estar inscrita como demandante de empleo en el ECyL. 


\begin{tabular}{|l|l|l|}
\hline Revista & & $\begin{array}{l}\text { Revista Latina de Sociologia (RELASO) } \\
\text { Vol. 9, núm. 2 (2019), pp. 24-58 } \\
\text { ISSN-e 2253-6469 } \\
\text { DoI: https://doi.org/10.17979/relaso.2019.9.2.6826 }\end{array}$ \\
de Sociologia & &
\end{tabular}

\section{Cronología}

La propuesta está creada para desarrollar un proyecto sociolaboral en un periodo de seis meses, con una fase de seguimiento de dos años. Lo que haría un total de dos años y medio desde el comienzo del proyecto hasta el final del seguimiento.

El proyecto previamente a ser implementado es debidamente organizado, y se puede explicar a través de varias fases. Las fases de la orientación sociolaboral son las a continuación mencionadas:

- Fase 1. De captación

- Fase 2. De acogida

- Fase 3. De diagnóstico

- Fase 4. De diseño del Itinerario

- Fase 5. De desarrollo del Itinerario

- Fase 6. De evaluación

- Fase 7. De inserción sociolaboral

- Fase 8. De seguimiento

\section{Fase 1. De captación}

La fase de captación se llevará a cabo a través de la base de datos de la entidad donde vaya a ser aplicada la propuesta de intervención, consultando qué mujeres atendidas por la entidad están en situación de desempleo, y tras la consulta, se inicia por parte de la figura profesional sociolaboral la toma de contacto con las mujeres que son atendidas y están en situación de desempleo, respondiendo a los siguientes puntos:

a) Ser atendida o haber sido atendida por la entidad de aplicación, o en su caso, estar en registradas en la base de datos por solicitud de servicios y/o recursos.

b) Estar en situación de desempleo actualmente.

c) Estar inscrita en el ECyL como demandante de empleo.

Tras la toma de contacto, se les informará que será un requisito que estén en proceso de búsqueda activa de empleo en el momento de iniciar el proyecto.

Tras la fase de captación, se incorporan al proyecto las 25 mujeres que, cumpliendo los requisitos desean participar en el proyecto de manera voluntaria.

\section{Fase 2. De acogida}

En la fase de acogida, las veinticinco mujeres que van a formar parte del proyecto son debidamente divididas en grupos. Estos grupos son elaborados teniendo en cuenta que las integrantes tengan semejantes características, entre ellas: edad, situación familiar, nivel formativo, entre otras cuestiones. La figura sociolaboral que dirija el proyecto sociolaboral va a ser la figura gestora de caso de cada una de las mujeres durante la propuesta. Entre las 


\begin{tabular}{|l|l|l|}
\hline Revista & & $\begin{array}{l}\text { Revista Latina de Sociología (RELASO) } \\
\text { Vol. 9, núm. 2 (2019), pp. 24-58 } \\
\text { ISSN-e 2253-6469 } \\
\text { DoI: https://doi.org/10.17979/relaso.2019.9.2.6826 }\end{array}$ \\
de Sociologia & &
\end{tabular}

competencias de la figura gestora de caso estará establecer comunicación con otros profesionales de la entidad, si fuera preciso, como también coordinarse con otros servicios que atienden a dichas mujeres y, además, ser el referente para las beneficiarias a lo largo del proceso.

Tras la división de los grupos, la orientadora sociolaboral procede a citar de manera individual a cada una de las mujeres, para comenzar a mantener una relación más cercana en el proceso. Por ello, en esta fase se llevarán a cabo un promedio de dos entrevistas con cada una de las beneficiarias a modo individual. Se explicará en qué consiste el proyecto, qué contenidos van a ser trabajados y qué objetivos generales persigue el proyecto. Tras llevar a cabo la toma de contacto con cada una de estas mujeres a lo largo de la fase de acogida, las concreciones y explicaciones, se procederá a la firma del contrato de compromiso. En este contrato se incorporarán unas cláusulas con las que se debe comprometer la usuaria.

\section{Fase 3. De diagnóstico}

Durante este periodo, para el cual se estima un mes, se realizan pruebas diagnósticas de manera individual a las diferentes mujeres y también test de motivación. El objetivo de realizar las pruebas y test es conocer el perfil de cada una de las mujeres. Dicho perfil y sus características ayudarán a generar el Itinerario.

En esta fase la profesional sociolaboral entrevistará a las veinticinco mujeres en tres diferentes ocasiones.

a) En una primera entrevista, se pregunta por las expectativas que tiene la mujer sobre la intervención en la que participa de forma voluntaria.

b) En una segunda entrevista, se le pasará a cada una de las mujeres unas pruebas diagnósticas con el objetivo de valorar su autoestima, su autoconocimiento, su asertividad, y sus habilidades sociales.

c) En la tercera entrevista se va a iniciar el proceso de valoración del nivel de empleabilidad de cada una de las mujeres y se realizará un test de motivación.

Finalmente, y tras las tres entrevistas personalizadas, de manera consensuada y conjunta, cada una de las mujeres establece con la gestora de caso, los objetivos que se quieren conseguir durante el desarrollo del proyecto.

\section{Fases 4 y 5. De diseño y desarrollo del Itinerario}

Tras toda la información recopilada anteriormente, se diseñará el Itinerario individualizado intensificado para cada una de las veinticinco mujeres. El desarrollo del proyecto tendrá una duración de seis meses. 


\begin{tabular}{|l|l|l|}
\hline Revista & & $\begin{array}{l}\text { Revista Latina de Sociologia (RELASO) } \\
\text { Vol. 9, núm. 2 (2019), pp. 24-58 } \\
\text { ISSN-e 2253-6469 } \\
\text { Dor: https://doi.org/10.17979/relaso.2019.9.2.6826 }\end{array}$ \\
de Sociologia & &
\end{tabular}

Durante el seguimiento del proyecto se trabajarán los beneficios, progresos, resistencias, etc., en cuanto a la búsqueda activa de empleo, a través de los recursos y estrategias ofrecidos, y en cuanto a las acciones formativas.

\section{Metodología de trabajo}

A lo largo de este proyecto se trabajan las áreas: social, psicológica, laboral y formativa de las mujeres participantes, de manera grupal, y a través de un Itinerario Individualizado de caso, que responderá a las necesidades particulares de cada usuaria. De este modo, con la propuesta se trabaja desde una perspectiva individualizada y también colectiva. Para lograr el trabajo grupal de la manera más exitosa posible se crean grupos reducidos con similares características entre las usuarias, para trabajar de forma homogénea.

El fin de esta metodología es generar pertenencia al grupo, y al mismo tiempo, trabajar las necesidades particulares de cada mujer, sin perder la intensidad de la labor.

La propuesta de intervención (Tabla 5) trabaja desde dos vertientes: la sociolaboral, y la compuesta por actividades de libre inscripción y realización. Las actividades sociolaborales están planteadas para ser trabajadas por parte de la figura del orientador sociolaboral. Las actividades de libre inscripción y realización (Tabla 6) están esbozadas para que los profesionales que las gestionen sean profesionales de la psicología, de la educación social, y desde el acompañamiento de profesionales del trabajo social.

En el presente trabajo se entiende que no se puede imponer la realización de determinadas actividades a las mujeres, ya que el fin último de la propuesta es el empoderamiento de las mismas, es decir, su autonomía, la capacidad de tomar sus propias decisiones. Por otro lado, se ha querido respetar el ritmo de las mujeres víctimas de violencia de género a la hora de plantear la presente propuesta de intervención.

Tabla 5. Actividades de la propuesta sociolaboral, obligatorias y de libre inscripción y realización.

\begin{tabular}{|c|c|}
\hline Actividades obligatorias & $\begin{array}{l}\text { Actividades de libre inscripción y } \\
\text { realización }\end{array}$ \\
\hline $\begin{array}{ll}\text { - } & \text { Trabajo de las habilidades sociales } \\
\text { - } & \text { Trabajo de las habilidades laborales } \\
\text { - } & \text { Role-playing } \\
\text { - } & \text { Itinerario Individualizado de Caso } \\
\text { - } & \text { Búsqueda activa de empleo por } \\
& \text { Internet }\end{array}$ & $\begin{array}{ll}\text { - } & \text { Grupo de Terapia para Mujeres } \\
\text { Maltratadas (una vez cada dos } \\
\text { - } & \text { Jemanas) } \\
\text { - } & \text { Danza } \\
\text { - } & \text { Relajación y expresión corporal } \\
\text { - } & \text { Talleres psicoeducativos }\end{array}$ \\
\hline
\end{tabular}

Fuente: elaboración propia. 


\section{Revista \\ Latina \\ de Sociologia}

Revista Latina de Sociología (RELASO)

Vol. 9, núm. 2 (2019), pp. 24-58

ISSN-e 2253-6469

DOI: https://doi.org/10.17979/relaso.2019.9.2.6826

Tabla 6. Desarrollo de las actividades de libre inscripción y realización.

\begin{tabular}{|c|c|}
\hline $\begin{array}{l}\text { Grupo de Terapia } \\
\text { para Mujeres } \\
\text { Maltratadas }\end{array}$ & $\begin{array}{l}\text { Los contenidos a tratar en dicha acción serían los que realmente se } \\
\text { trabajan desde P.1 en la práctica: } \\
\text { - Unidad 1. Presentación del grupo } \\
\text { - Unidad 2. Explicar el maltrato (causas y consecuencias) } \\
\text { - Unidad 3. Estereotipos de género } \\
\text { - Unidad 4. Autoestima } \\
\text { - Unidad 5. Técnicas de manejo del estrés y control de la } \\
\text { ansiedad }\end{array}$ \\
\hline Jiu-jitsu & \multirow[b]{3}{*}{$\begin{array}{l}\text { En primer lugar, el ejercicio físico genera beneficios a nivel físico y } \\
\text { a nivel psicológico para la persona, ya que ayuda a mantener un } \\
\text { hábito de vida saludable y libera endorfinas. Por otro lado, pone a la } \\
\text { gente en contacto, creando ambientes de unión, lo que favorece la } \\
\text { ampliación de los nodos. Y, por último, la actividad física aporta } \\
\text { mayor autoconfianza y sensación de bienestar. Las actividades } \\
\text { planteadas son de diferentes índoles, siendo una de ellas de defensa } \\
\text { personal, otra de ellas de relajación y contacto con el cuerpo, y la } \\
\text { otra, danza, una actividad aeróbica y grupal. Se han planteado } \\
\text { diferentes tipos de actividad para responder a las necesidades de cada } \\
\text { usuaria. }\end{array}$} \\
\hline Danza & \\
\hline $\begin{array}{l}\text { Relajación y } \\
\text { expresión corporal }\end{array}$ & \\
\hline & $\begin{array}{l}\text { Los contenidos a tratar en dicha acción serían los que realmente se } \\
\text { trabajan desde P.1 en la práctica: } \\
\text { - Igualdad de Oportunidades entre Mujeres y Hombres } \\
\text { - Violencia de Género } \\
\text { - Aspectos jurídicos en tema de la Violencia de Género } \\
\text { - Trastornos de ansiedad y depresión } \\
\text { - Salud femenina y sexualidad } \\
\text { Tanto a nivel social como a nivel personal se persigue con la } \\
\text { propuesta de intervención trabajar los estilos de afrontamiento de } \\
\text { cada una de las mujeres, la motivación de las mismas, la autodefensa, }\end{array}$ \\
\hline
\end{tabular}

Rev.Lat.Soc. Vol. 9(1) (2019) pp. 24-58. 


\begin{tabular}{|l|l|l|}
\hline Revista & & $\begin{array}{l}\text { Revista Latina de Sociología (RELASO) } \\
\text { Vol. 9, núm. 2 (2019), pp. 24-58 } \\
\text { ISSN-e 2253-6469 } \\
\text { Dotina } \text { https://doi.org/10.17979/relaso.2019.9.2.6826 }\end{array}$ \\
\hline
\end{tabular}

\begin{tabular}{|l|l|}
\hline $\begin{array}{l}\text { la autoestima, la asertividad, el autoconocimiento, el equilibrio } \\
\text { emocional, las habilidades sociales y las habilidades laborales. Con }\end{array}$ \\
los objetivos de: \\
a. Aminorar sus niveles de ansiedad, miedo, inseguridad y \\
depresión. \\
b. Mejorar sus habilidades sociales y laborales. \\
c. Ofrecer herramientas para el mantenimiento de vínculos \\
d. Faludables.
\end{tabular}

Fuente: elaboración propia.

Para el desarrollo de las acciones obligatorias en la orientación sociolaboral se prestan listas de recursos, que, dentro del contexto de la Comunidad Autónoma de Castilla y León, y en el municipio de Valladolid, pueden responder a las demandas presentadas (Figuras 5, 6 y 7). 


\begin{tabular}{|l|l|l|}
\hline Revista & & $\begin{array}{l}\text { Revista Latina de Sociologia (RELASO) } \\
\text { Vol. 9, núm. 2 (2019), pp. 24-58 } \\
\text { ISSN-e 2253-6469 } \\
\text { Datina }\end{array}$ \\
de Sociologs://doi.org/10.17979/relaso.2019.9.2.6826 & \\
\hline
\end{tabular}

Figura 5. Recursos para la orientación sociolaboral en materia de juventud y becas, subvenciones y empleo.

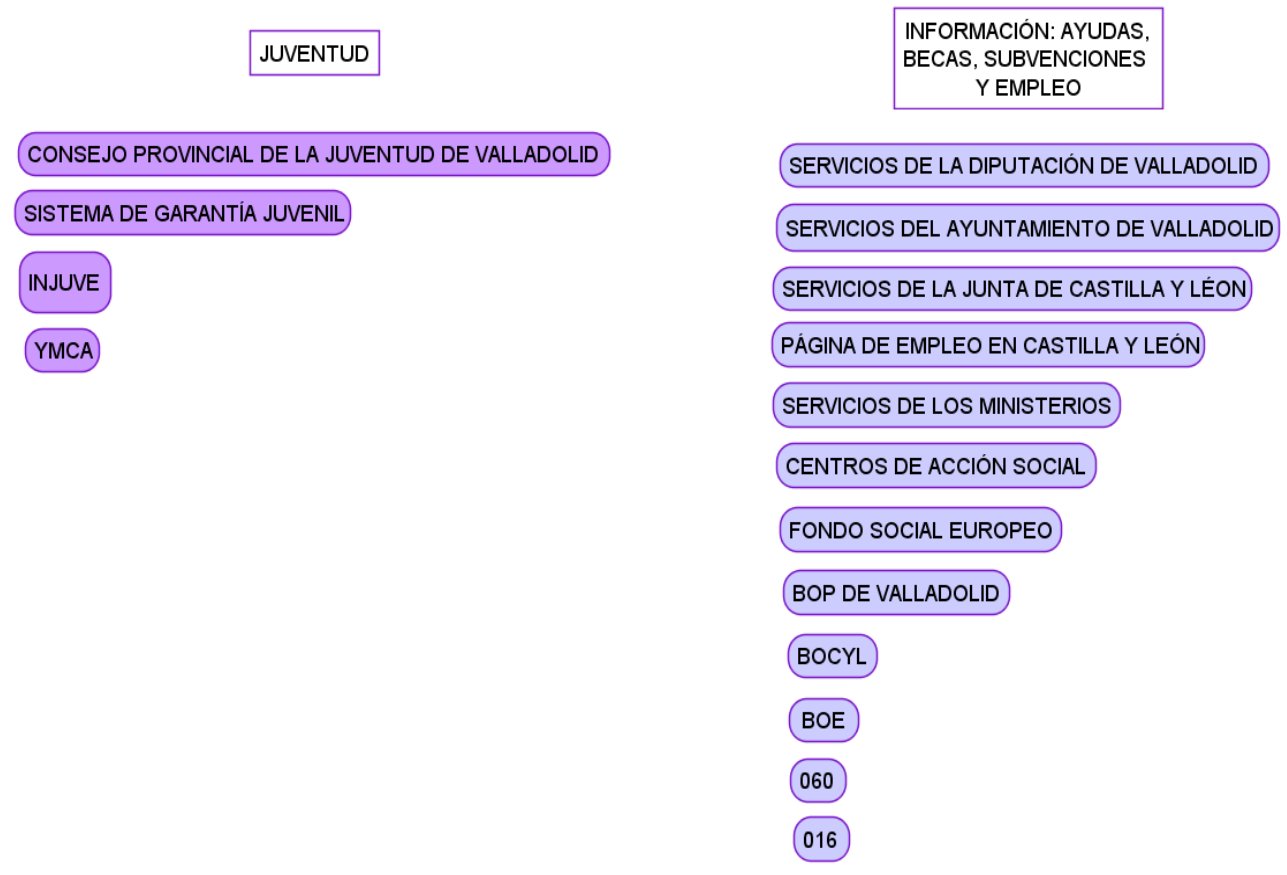

Fuente: Elaboración propia. 


\begin{tabular}{|l|l|l|}
\hline Revista & & $\begin{array}{l}\text { Revista Latina de Sociología (RELASO) } \\
\text { Vol. 9, núm. 2 (2019), pp. 24-58 } \\
\text { ISSN-e 2253-6469 } \\
\text { Dotin https://doi.org/10.17979/relaso.2019.9.2.6826 }\end{array}$ \\
\hline de Sociologia & &
\end{tabular}

Figura 6. Recursos para la orientación sociolaboral en materia de empleo y emprendimiento.



Fuente: Elaboración propia. 


\begin{tabular}{|l|l|l|}
\hline Revista & & $\begin{array}{l}\text { Revista Latina de Sociología (RELASO) } \\
\text { Vol. 9, núm. 2 (2019), pp. 24-58 } \\
\text { ISSN-e 2253-6469 } \\
\text { Dotin https://doi.org/10.17979/relaso.2019.9.2.6826 }\end{array}$ \\
\hline de Sociologia & &
\end{tabular}

Figura 7. Recursos para la orientación sociolaboral en materia de formación y ayudas.

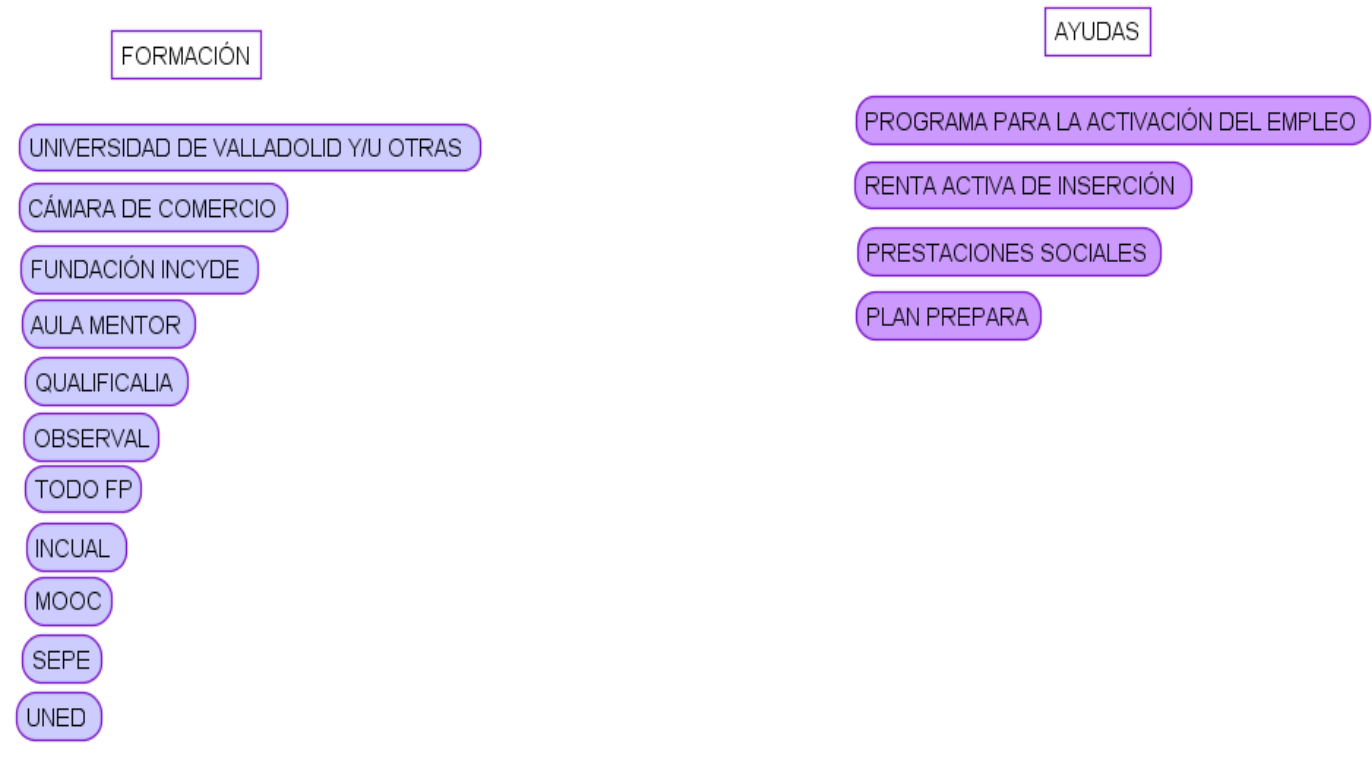

Fuente:Elaboración propia.

A continuación, se presenta una aclaración sobre algunas de las nomenclaturas de los posibles servicios y recursos mencionados: INJUVE: Instituto de la Juventud; YMCA: movimiento mundial de personas que se unen por el compromiso compartido de fortalecer, acompañar y dar herramientas a los jóvenes; BOP DE VALLADOLID: Boletín Oficial de la Provincia de Valladolid; BOCYL: Boletín Oficial de Castilla y León; BOE: Boletín Oficial del Estado; PROGRAMA PYCE: Programa de Plan de Empleo Joven; EURES: EURopean Employment Services; INEM: Instituto Nacional de Empleo; SEPE: Servicio Público de Empleo Estatal; ECLAP: Escuela de Administración Pública de Castilla y León; PORTAL PYME: Portal de Pequeña y Mediana Empresa; CEPYME: Confederación Española de la Pequeña y Mediana Empresa; CIRCE: Centro de Información y Red de Creación de Empresas; INCUAL: Instituto Nacional de las Cualificaciones; MOOC: Massive Open Online Course; UNED: Universidad Nacional de Educación a Distancia.

Todas las actividades del bloque de obligada realización son implementadas por la orientadora sociolaboral, como gestora de caso.

Itinerario Individualizado de Caso

El Itinerario Individualizado de Caso con cada una de las mujeres consistirá en un proceso individual que coordinará la gestora de caso con el objeto de plantear objetivos a corto, a medio y a largo plazo, de los que surgirán posibles acciones a llevar a cabo. Dichas acciones serán implementadas a través de una técnica y evaluada por medio de un ítem. Tanto los objetivos como las propuestas se plantearán de manera conjunta con la beneficiaria, dando voz y sentido a sus necesidades e intereses. 


\begin{tabular}{|l|l|l|}
\hline Revista & & $\begin{array}{l}\text { Revista Latina de Sociologia (RELASO) } \\
\text { Vol. 9, núm. 2 (2019), pp. 24-58 } \\
\text { ISSN-e 2253-6469 } \\
\text { Dor: https://doi.org/10.17979/relaso.2019.9.2.6826 }\end{array}$ \\
de Sociologia & &
\end{tabular}

El Itinerario se planteará teniendo en cuenta las variables estudiadas y mencionadas en la fase de acogida y de diagnóstico, teniendo también en cuenta diferentes aspectos como: el estudio de la empleabilidad de la mujer, acciones formativas cursadas previamente, preferencias formativas, experiencia laboral y anhelos laborales.

Para llevar a cabo este Itinerario se realizarán acciones como, entrevistas individuales con la gestora de caso, donde se abordarán aspectos como:

- Informar a cada una de las beneficiarias del proyecto de las diferentes opciones formativas a las cuales puede optar en función de su nivel formativo, teniendo en cuenta su experiencia laboral, formación previa e intereses.

- Ofertar una serie de acciones formativas que tal y como establece el Observatorio de las Ocupaciones (Servicio Público de Empleo Estatal, 2020) en estos momentos tienen salida profesional.

- Dar la importancia suficiente a la formación, para que cada mujer participe en al menos en una opción formativa de las ofertadas, o cualquier otra. El impacto y beneficio de dicha formación será evaluado en el seguimiento del proyecto.

- Facilitación de prácticas en empresa, como parte del currículum formativo de la oferta en la que se matricule la persona.

- Recomendación de acreditar las competencias en aquellos casos donde la mujer tenga una experiencia laboral demostrable por medio de recursos como la vida laboral.

- Preparación del currículum y la carta de presentación.

- Definición del objetivo profesional con cada una de las mujeres, y redacción de la carta de motivación.

- Preparación de entrevista de trabajo.

- Apoyo en la búsqueda activa de empleo.

- Fomento del espíritu emprendedor, para la posible acción emprendedora de cada una de las mujeres.

- Estudio de los nodos sociales y familiares de cada una de las mujeres con el objetivo de ir mejorando y ampliando el mismo a lo largo de proyecto.

- Estudio DAFO (debilidades, amenazas, fortalezas y oportunidades) de la beneficiaria, para fomentar el progreso y evolución a partir de sus potencialidades, tratando de aminorar las debilidades, como si de un campo de fuerza se tratase.

Además, en aquellos casos en los que sea posible trabajar con los familiares que representan vínculos saludables y de apoyo para la mujer, y el entorno cercano a la persona, se contará con ellos en las entrevistas individualizadas y si fuera preciso, en la intervención para la mejora de la esfera sociolaboral de la mujer.

Acciones formativas planteadas en el Itinerario Individualizado 


\begin{tabular}{|l|l|l|}
\hline Revista & & $\begin{array}{l}\text { Revista Latina de Sociologia (RELASO) } \\
\text { Vol. 9, núm. 2 (2019), pp. 24-58 } \\
\text { ISSN-e 2253-6469 } \\
\text { Dor: https://doi.org/10.17979/relaso.2019.9.2.6826 }\end{array}$ \\
de Sociologia & &
\end{tabular}

Como se ha señalado en la investigación del perfil predominante obtenido, no más de la mitad de las destinatarias de las entidades del estudio tienen estudios superiores. Por este motivo un elemento clave de la intervención es la orientación para la formación.

La amplitud de formación hacia la que se puede orientar es la reflejada en la siguiente figura.

Figura 8. Recursos formativos por niveles EQF-MEC.

ORIENTACIÓN HACIA LA FORMACIÓN REGLADA
GRADUADO EN ESO/GRADUADO ESCOLAR
BACHILLERATO
FORMACIONN PROFESIONAL BÁSICA
CICLOS FORMATIVOS DE GRADO MEDIO
CICLOS FORMATIVOS DE GRADO SUPERIOR
CERTIFICADO PROFESIONAL DE NIVEL 1
CERTIFICADO PROFESIONAL DE NIVEL 2
CERTIFICADO PROFESIONAL DE NIVEL 3
ESTUDIOS UNIVERSITARIOS DE GRADO
ESTUDIOS UNIVERSITARIOS DE MÁSTER
ESTUDIOS UNIVERSITARIOS DE TITULO PROPIO
ESTUDIOS UNIVERSITARIOS DE DOCTORADO

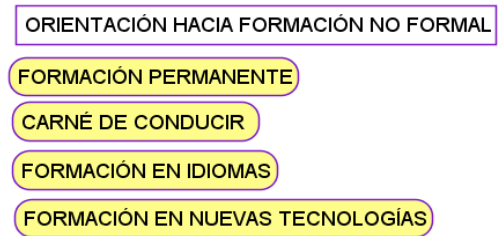

Fuente: Elaboración propia.

Con respecto a las opciones: Tanto los certificados de profesionalidad como la formación profesional están compuestos por unidades de competencia. En el caso de los certificados, la cualificación profesional se divide en unidades de competencias. Son esas unidades de competencia las que se pueden acreditar a través de la experiencia. A su vez las unidades de competencia se dividen en módulos formativos y estos, en unidades formativas.

Por último, el perfil con el que se trabaja tiene familiares a cargo, por todo ello se tendrán en cuenta no solo las ofertas educativas presenciales, sino también a distancia, para la posible conciliación familiar.

\section{Acreditación de competencias}

Las mujeres que cumplan alguno de los requisitos que establece el Servicio Público de Empleo Estatal (2020) podrán solicitar la acreditación de competencias. La orientadora sociolaboral deberá recomendar en aquellos casos donde sea posible la acreditación, que hagan la misma con el objetivo de ampliar sus opciones laborales.

Orientación hacia el autoempleo

En aquellos casos, en los que las mujeres tengan una idea de negocio o espíritu emprendedor, la orientadora sociolaboral solicitará a la mujer que realice un Test de 


\begin{tabular}{|l|l|l|}
\hline Revista & & $\begin{array}{l}\text { Revista Latina de Sociología (RELASO) } \\
\text { Vol. 9, núm. 2 (2019), pp. 24-58 } \\
\text { ISSN-e 2253-6469 } \\
\text { DoI: https://doi.org/10.17979/relaso.2019.9.2.6826 }\end{array}$ \\
de Sociologia & &
\end{tabular}

autodiagnóstico de actitudes emprendedoras. Además, se la recomendará contactar con organismos donde puede ser orientada como las Cámaras de Comercio, CEPYME (Confederación Española de la Pequeña y Mediana Empresa), el Centro de Información y Red de Creación de Empresas (CIRCE), el Portal PYME (Pequeña y Mediana Empresa) la Plataforma de Apoyo al Emprendimiento, e indagar en fundaciones como la Fundación Tomillo. Posteriormente, se procederá a esbozar con la mujer la programación de objetivos y acciones a corto, medio y largo plazo, del proyecto.

Habilidades sociales y laborales

Es necesario trabajar las habilidades sociales con este colectivo, puesto que la situación vivida las lleva en muchas ocasiones a un estilo comunicativo pasivo, de culpabilidad y sumisión. Trabajar las habilidades sociales con ellas las permitirá un estilo comunicativo asertivo, que permita defender sus ideas, pensamientos y sentimientos. Por otro lado, la mejora de las habilidades social generará beneficio a la hora de ampliar sus nodos, y ayudará a perder el miedo a la socialización.

Los contenidos se trabajarían a través de un sistema de trabajo dinámico, por medio de dinámicas y juegos, además, en otras sesiones se realizaría role-playing grupal. Igualmente, sería con las habilidades laborales.

Búsqueda activa de empleo por internet

La búsqueda activa de empleo por Internet ayuda a la mujer a adquirir dominio del uso de las nuevas tecnologías, al tiempo en que se busca empleo, se contacta con empresas y se informan de nuevas ofertas de manera diaria.

Una vez a la semana todas podrán acudir con la orientadora a realizar búsqueda activa por internet, no obstante, además, durante el resto de la semana podrían y deberían acudir a los servicios del Centro Cívico utilizados, para completar esta acción, si no es realizada desde casa.

\section{Fase 7. De inserción sociolaboral}

La inserción sociolaboral de la mujer puede ser tanto por cuenta ajena como por cuenta propia, fruto de una acción de autoempleo. En cualquiera de los casos es preciso conocer el perfil de la oferta de empleo y valorar si el perfil de la mujer responde a la oferta. 


\begin{tabular}{|l|l|l|}
\hline Revista & & $\begin{array}{l}\text { Revista Latina de Sociología (RELASO) } \\
\text { Vol. 9, núm. 2 (2019), pp. 24-58 } \\
\text { ISSN-e 2253-6469 } \\
\text { DoI: https://doi.org/10.17979/relaso.2019.9.2.6826 }\end{array}$ \\
de Sociologia & &
\end{tabular}

Fases 6 y 8. De evaluación y de seguimiento

La evaluación del proyecto sigue el esquema de la Figura 9.

Figura 9. Esquema de la evaluación y seguimiento de la propuesta de intervención.


Fuente: elaboración propia.

Para realizar la evaluación inicial se llevaría una entrevista inicial de enfoque cualitativo que irá destinada a la obtención de información sobre las expectativas de las beneficiarias. La evaluación de monitorización se realizaría por medio de la observación directa que sería recogida a través de un diario de campo. Al final del proyecto se llevaría a cabo un postest, a modo de cuestionario, centrado en los beneficios que han encontrado en el proyecto las participantes. Y finalmente, en la fase de seguimiento de los dos años, se pediría a las mujeres que realizasen un cuestionario de satisfacción de la gestión de ofertas de empleo e inserción sociolaboral. Se mantendría el contacto por medio de entrevistas una vez al mes para estudiar el proceso, los cambios que se van produciendo, el transcurso formativo de cada mujer y si han encontrado empleo. Por medio de estas entrevistas se enfatizaría individualmente en aquellos aspectos que fueran necesarios.

\section{Conclusiones}




\section{Revista \\ Latina \\ de Sociologia}

Revista Latina de Sociología (RELASO)

Vol. 9, núm. 2 (2019), pp. 24-58

ISSN-e 2253-6469

DOI: https://doi.org/10.17979/relaso.2019.9.2.6826

Se presentaba como objetivo general el planteamiento de una propuesta de intervención, centrada en la persona y ajustada a las necesidades específicas del contexto del estudio. Como se ha presentado en el trabajo, la propuesta ha sido diseñada en su totalidad conforme a los resultados objetivos para los dos objetivos específicos: el perfil de la mujer atendida y las tareas de orientación sociolaboral desarrolladas desde las entidades en el momento del estudio.

En primer lugar, se puede concluir la necesidad real de atender al perfil formativo, laboral y familiar de las mujeres destinatarias de la propuesta. Si bien la intervención se diseña en base a sus preferencias y necesidades individuales, una necesidad compartida en el 75\% de los casos, es la de continuar la formación, para ampliar el espectro profesional. Y es importante hacerlo sin descuidar los nodos familiares y teniendo en cuenta la conciliación laboral y familiar. Por ello, a lo largo del Itinerario de caso se ofrece asesoramiento sobre ayudas que puedan contribuir al apoyo de la mujer, tanto a nivel económico, como laboral y formativo. Por otra parte, si bien algunas de las entidades participantes vienen desarrollando sus labores sociolaborales desde hace algún tiempo, otras de ellas no cuentan con los suficientes recursos humanos, económicos o espacio-temporales para la incorporación de este asesoramiento a su cartera de servicios. Es importante seguir trabajando en esta línea, construyendo tejido social con las entidades que sí disponen del asesoramiento estudiado para dar respuesta a las demandas existentes. El objetivo no es duplicar servicios, si no dar soluciones, y la coordinación entre entidades y organismos en este sentido es fundamental, tal y como se estudió en el sistema categorial.

\section{Discusión}

En la pregunta de investigación se planteaba cuál es la relevancia que implica la orientación sociolaboral en relación con el empoderamiento integral de la mujer víctima de violencia de género. Como así se ha constatado en el estudio empírico llevado a cabo, las mujeres atendidas por las entidades del Tercer Sector participantes presentan multicausalidad de exclusión social, identificando así casos donde conviven la violencia de género y el desempleo, combinación que abordan también Delgado et al. (2007), Delgado-Álvarez et al. (2012) y Vicente \& Martínez (2010), con otras realidades como baja experiencia profesional o baja cualificación profesional, lo que deriva en la necesidad de potenciar estos dos elementos (López, 2017; Lorente \& Lorente, 1998; Ortiz, 2013). Añadido a ello, existen otros elementos presentes como las responsabilidades familiares, o los escasos nodos de apoyo familiares y sociales. Dado que el objetivo perseguido es frenar las causas de exclusión social, en este caso de brecha de género en el ámbito laboral con comorbilidad con violencia de género, como defiende Hunnicutt (2009), el papel que sostiene la orientación sociolaboral en este sentido es fundamental (Sevillano, 2017; Verdugo-Castro, 2019), y así lo defienden las personas entrevistadas en las entidades, quienes ya vienen trabajando en esta línea o reclaman mayor disposición de recursos para hacerlo. Este papel de la orientación sociolaboral, así mismo lo sostienen otros autores, quienes apuestan por este asesoramiento como camino de mejora para la persona (García, 2019; Izquierdo \& Farías, 2018; Laparra 


\begin{tabular}{|l|l|l|}
\hline Revista & & $\begin{array}{l}\text { Revista Latina de Sociologia (RELASO) } \\
\text { Vol. 9, núm. 2 (2019), pp. 24-58 } \\
\text { ISSN-e 2253-6469 } \\
\text { Dor: https://doi.org/10.17979/relaso.2019.9.2.6826 }\end{array}$ \\
de Sociologia & &
\end{tabular}

et al., 2007). Por último, recordar que la meta final es el empoderamiento integral del sujeto, lo que conlleva trabaja desde un enfoque integrador.

\section{Limitaciones y prospectiva}

El estudio presentado no está libre de limitaciones. En primer lugar, el acercamiento a las entidades ha sido difícil y prolongado en el tiempo por la protección de las usuarias y del entorno donde se las atiende. $\mathrm{Y}$, en segundo lugar, por la delicadeza del estudio y los procesos de acercamiento a las asociaciones, no ha sido posible extender la investigación a otras ciudades y Comunidades Autónomas. En vistas al futuro, uno de los principales propósitos es precisamente extender esta investigación a otras ciudades, para así poder establecer un estudio comparado entre realidades, y contemplar una propuesta de intervención extensible en diferentes contextos.

\section{Agradecimientos}

Este trabajo ha sido realizado dentro del Programa de Doctorado de Formación en la Sociedad del Conocimiento de la Universidad de Salamanca (García-Peñalvo, 2014) y con financiación del Ministerio de Ciencia, Innovación y Universidades de España a través de una beca FPU (FPU017/01252).

\section{Referencias bibliográficas}

Andréu Abela, J. (2000). Las técnicas de Análisis de Contenido: Una revisión actualizada. Fundación Centro Estudios Andaluces, Universidad de Granada, 10(2), 1-34.

Anguera, M. T. (1999). Hacia una evaluación de la actividad cotidiana y su contexto: ¿presente o futuro para la metodología? Discurso de ingreso como académica numeraria electa. Real Academia de Doctors.

Blackburn, H. (2017). The Status of Women in STEM in Higher Education: A Review of the Literature 2007-2017. Science and Technology Libraries, 36(3), 235-273. https://doi.org/10.1080/0194262X.2017.1371658

Codiroli Mcmaster, N. (2017). Who studies STEM subjects at A level and degree in England? An investigation into the intersections between students' family background, gender and ethnicity in determining choice. British Educational Research Journal, 43(3), 528-553. https://doi.org/10.1002/berj.3270

Datosmacro. (s. f.). Desempleo 2020. datosmacro.com. Recuperado 8 de enero de 2020, de https://datosmacro.expansion.com/paro

Delegación del Gobierno para la Violencia de Género. (2019). Portal Estadístico Violencia de Género. http://estadisticasviolenciagenero.igualdad.mpr.gob.es/ 


\begin{tabular}{|l|l|l|}
\hline Revista & $\begin{array}{l}\text { Revista Latina de Sociología (RELASO) } \\
\text { Vol. 9, núm. 2 (2019), pp. 24-58 } \\
\text { ISSN-e 2253-6469 } \\
\text { Dot: https://doi.org/10.17979/relaso.2019.9.2.6826 }\end{array}$ \\
\hline
\end{tabular}

Delgado Álvarez, C., Iraegui Torralba, A., Marquina Torres, L., Martín Tabernero, M. F., Palacios Vicario, B., Plaza Sánchez, J. F., Sendín Melguizo, P. P., Pérez Grande, M. D., Revulta Domínguez, I., \& Sánchez Gómez, M. C. (2007). Patrones de masculinidad y feminidad asociados al ciclo de la violencia de género. Revista de Investigación Educativa, 25(1), 187-217.

Delgado-Álvarez, M. C., Sánchez Gómez, M. C., \& Fernández-Dávila Jara, P. A. (2012). Gender Attributes and Stereotypes Associated with the Cycle of Violence Against Women. Universitas Psychologica, 11(3), 769-777.

Diekman, A. B., Brown, E. R., Johnston, A. M., \& Clark, E. K. (2010). Seeking Congruity Between Goals and Roles: A New Look at Why Women Opt Out of Science, Technology, Engineering, and Mathematics Careers. Psychological Science, 21(8), 1051-1057. https://doi.org/10.1177/0956797610377342

European Institute of Gender Equality. (2018). Overview | Gender Statistics Database. EIGE. https://eige.europa.eu/gender-statistics/dgs

Expósito, F. (2011). Violencia de género. 6.

García García, M. del C. (2019). Orientación para el empleo en la región de murcia: Análisis de necesidades e identificación de buenas prácticas [Http://purl.org/dc/dcmitype/Text, UNED. Universidad Nacional de Educación a Distancia (España)]. https://dialnet.unirioja.es/servlet/tesis?codigo=247435

García-Holgado, A., Mena, J., García-Peñalvo, F. J., \& González, C. (2018). Inclusion of gender perspective in Computer Engineering careers. Elaboration of a questionnaire to assess the gender gap in Tertiary Education. En 2018 IEEE Global Engineering Education Conference (EDUCON) (pp. 1553-1560).

García-Peñalvo, F. J. (2014). Formación en la sociedad del conocimiento, un programa de doctorado con una perspectiva interdisciplinar. Education in the Knowledge Society, 15(1), 4-9.

Guerra, J. A. (2014). ¿Qué hay detrás de la muerte de mujeres a manos de sus parejas masculinas? Hacia un análisis del concepto "violencia de género". Revista de Metodología de Ciencias Sociales, 28, 129-156.

Hunnicutt, G. (2009). Varieties of Patriarchy and Violence against Women: Resurrecting 'Patriarchy' as a Theoretical Tool. Violence Against Women, 15(5), 553-573.

Instituto Nacional de Estadística. (2019). Instituto Nacional de Estadística. https://www.ine.es/

Izquierdo Rus, T., \& Farías, A. J. (2018). Empleabilidad y expectativa de logro en la inserción laboral de los estudiantes universitarios. Revista Española de Orientación y Psicopedagogía, 29(2), 29-40.

Junta de Castilla y León. (2015). Directrices de funcionamiento Objetivo Violencia Cero. Consejera de Familia e Igualdad de Oportunidades. Recuperado 8 de noviembre de 2018, https:/familia.jcyl.es/web/jcyl/Familia/es/Plantilla100Detalle/1246988964069/Nor mativa/1284483862824/Redaccion 


\begin{tabular}{|l|l|l|}
\hline Revista & & $\begin{array}{l}\text { Revista Latina de Sociologia (RELASO) } \\
\text { Vol. 9, núm. 2 (2019), pp. 24-58 } \\
\text { ISSN-e 2253-6469 } \\
\text { Dor: https://doi.org/10.17979/relaso.2019.9.2.6826 }\end{array}$ \\
de Sociologia & &
\end{tabular}

Laparra, M., Pérez, B., García, J. R., Iturbide, R., \& Resaño, Y. (2007). Procesos de exclusión e itinerarios de inserción. La acción de Cáritas en el espacio de la exclusión, nuevos retos para la intervención social. Fundación FOESSA.

López Merchán, R. (2017). La situación de las mujeres inmigrantes víctimas de violencia de género desde la visión de las y los profesionales: Castilla y León como ámbito geográfico de estudio [Http://purl.org/dc/dcmitype/Text, UNED. Universidad Nacional de Educación a https://dialnet.unirioja.es/servlet/tesis?codigo=139833

Lorente, M., \& Lorente, J. A. (1998). Agresión a la mujer: Maltrato, violación y acoso; entre la realidad social y el mito cultural. Editorial Comares.

Martos Martínez, Á., Simón Márquez, M. del M., Barragán Martín, A. B., Molero Jurado, M. del M., Pérez-Fuentes, M. del C., \& Gázquez Linares, J. J. G. (2016). Revisión del uso de las nuevas tecnologías para la intervención en violencia de género en parejas de adolescentes. European Journal of Child Development, Education and Psychopathology, 4(1), 63-73.

Ministerio de Sanidad, Servicios Sociales e Igualdad. (2015). Macroencuesta de violencia contra la mujer 2015. Ministerio de Sanidad, Política Social e Igualdad.

Ministerio de Sanidad, Servicios Sociales e Igualdad - Delegación del Gobierno para la Violencia de Género. (2017). Estadísticas, encuestas, estudios e investigaciones. http://www.violenciagenero.igualdad.mpr.gob.es/violenciaEnCifras/home.htm

Organización Mundial de la Salud. (2013). OMS | Informe de la OMS destaca que la violencia contra la mujer es "un problema de salud global de proporciones epidémicas".

WHO. https://www.who.int/mediacentre/news/releases/2013/violence_against_women_20 130620/es/

Organización Mundial de la Salud. (2017). Violencia contra la mujer. https://www.who.int/es/news-room/fact-sheets/detail/violence-against-women

Ortiz Calle, M. E. (2013). Violencia de género. Nuevo derecho, 9(12), 57-68.

Puente-Martínez, A., Ubillos-Landa, S., Echeburúa, E., \& Páez-Rovira, D. (2016). Factores de riesgo asociados a la violencia sufrida por la mujer en la pareja: Una revisión de meta-análisis y estudios recientes. Anales de Psicología, 32(1).

Sánchez Gómez, M. (2015). Metodología de investigación en Pedagogía Social (Avance Cualitativo y Modelos Mixtos). Pedagogía Social. Revista Interuniversitaria, 26. http://www.redalyc.org/resumen.oa?id=135043653001

Servicio Público de Empleo Estatal. (2020). Certifica tu experiencia laboral. Servicio Público de Empleo Estatal. /HomeSepe/Personas/formacion/certifica-tu-experiencialaboral.html

Sevillano Monje, V. (2017). Las empresas de inserción como salida laboral para las personas en riesgo de exclusión social. Cuestiones pedagógicas: Revista de ciencias de la educación, 26, 131-144. 


\begin{tabular}{|l|l|l|}
\hline Revista & & $\begin{array}{l}\text { Revista Latina de Sociologia (RELASO) } \\
\text { Vol. 9, núm. 2 (2019), pp. 24-58 } \\
\text { ISSN-e 2253-6469 } \\
\text { Dor: https://doi.org/10.17979/relaso.2019.9.2.6826 }\end{array}$ \\
de Sociologia & &
\end{tabular}

Souza, F. N., Costa, A. P., \& Moreira, A. (2011). Análise de Dados Qualitativos Suportada pelo Software WebQDA. Atas da VII Conferência Internacional de TIC na Educação: Perspetivas de Inovação (CHALLANGES2011), 49-56.

Subirats, J., Riba, C., Giménez, L., Obradors, A., Giménez, M., Queralt, D., Bottos, P., \& Rapoport, A. (2004). Pobreza y exclusión social. Colección Estudios Sociales, 16, 189.

Verdugo-Castro, S., Sánchez-Gómez, M. C., García-Holgado, A., \& García-Peñalvo, F.J. (2019). Revisión y estudio cualitativo sobre la brecha de género en el ámbito educativo STEM por la influencia de los estereotipos de género. En A. P. Costa, I. Pinho, B. M. Faria, \& L. P. Reis (Eds.), Atas-Investigação Qualitativa em Ciências Sociais/Investigación Cualitativa en Ciencias Sociales (Vol. 3, pp. 381-386).

Verdugo-Castro, Sonia. (2019). Detection of needs in the lines of work of third sector entities for unemployed women in situations of social exclusion. Pedagogía Social. Revista Interuniversitaria, 0(34). https://doi.org/10.7179/PSRI_2019.34.12

Vicente, A. M., \& Martínez, T. (2010). Cambios en el mercado laboral español. La incorporación de la mujer al mercado laboral: Factores determinantes a nivel geográfico, profesional y por actividades en el sistema de la Seguridad Social. Gobierno de España. Secretaría de Estado de Seguridad Social.

Wardetrudis, U. (2015). Mediación y violencia de género. Universidad de Murcia.

Winterbotham, M. (2014). The UK Commission's Employer Skills Survey 2013: UK Results. London, UK Commission, 200. 